\title{
High expression of retinoic acid receptors and synthetic enzymes in the human hippocampus
}

\author{
Yara Dadalti Fragoso $\cdot$ Kirsty D. Shearer • \\ Angelo Sementilli • Leda Viegas de Carvalho • \\ Peter J. McCaffery
}

Received: 16 August 2011/Accepted: 20 October 2011/Published online: 11 November 2011

(C) The Author(s) 2011. This article is published with open access at Springerlink.com

\begin{abstract}
Retinoic acid, the active form of the nutrient vitamin $A$, regulates several facets of neuronal plasticity in the hippocampus, including neurogenesis and synaptic strength, acting via specific retinoic acid receptors (RARs). Essential for conversion of vitamin A to retinoic acid is the enzyme retinaldehyde dehydrogenase (RALDH) and in the rodent hippocampus this is only present in the adjacent meninges where it must act as a locally released paracrine hormone. Little is known though about the expression of RALDHs and RARs in the human hippocampus. This study confirms that RALDH levels are very low in mouse neurons but, surprisingly, strong expression of RALDH protein is detected by immunohistochemistry in hippocampal neurons. The receptors $\operatorname{RAR} \alpha, \beta$ and $\gamma$ were also detected, each receptor exhibiting differing subcellular locations implying their potential regulation of both transcription and non-genomic actions. These results imply an essential
\end{abstract}

Y. D. Fragoso and K. D. Shearer are joint first authors.

Y. D. Fragoso

Department of Neurology, Universidade Metropolitana de

Santos, Santos, SP, Brazil

Y. D. Fragoso · K. D. Shearer · P. J. McCaffery $(\bowtie)$ Institute of Medical Sciences, University of Aberdeen, School of Medical Sciences, Foresterhill,

Aberdeen AB25 2ZD, Scotland, UK

e-mail: p.j.mccaffery@abdn.ac.uk

\section{A. Sementilli}

Department of Physiopathology,

Universidade Metropolitana de Santos and Centro

Universitario Lusíada, Santos, SP, Brazil

L. V. de Carvalho

Department of Pathology, Centro Universitário Lusíada,

Santos, SP, Brazil function of retinoic acid in the human hippocampus likely to include regulation of neuronal plasticity.

Keywords Vitamin A - Retinaldehyde dehydrogenase . Retinoic acid receptor · Hippocampus · Dentate gyrus . CA1

\section{Introduction}

The nuclear receptor superfamily of transcriptional regulators includes a number of receptors for lipid hormones including oestrogen, androgen, thyroid hormone and the corticosteroids. Several other receptors in this family are for lipid hormone-like ligands; this includes vitamin D, which through its activation and release by the kidney functions as a paracrine hormone (Bell 1985) while vitamin A through its active metabolite retinoic acid (RA) functions as a locally released paracrine or autocrine hormone, acting via retinoic acid receptors (RARs). The retinoid X receptors (RXRs) can heterodimerise with vitamin D receptor and RARs as well as the thyroid hormone receptors (Shaffer and Gewirth 2004; Glass 1996). Vitamin A is stored in the body as retinyl esters which are hydrolysed and released as retinol to maintain a constant $1 \mu \mathrm{M}$ concentration of retinol in the plasma, bound to retinol-binding protein (Blomhoff 1994). Cells actively take up retinol and oxidise this to RA which diffuses locally to activate nearby cells (Blomhoff 1994).

This system is essential for development of many organ systems in the embryo (Sporn et al. 1994) including the CNS (McCaffery et al. 2003), but its importance for the postnatal brain has only been relatively recently recognised. The hippocampus had been an area of particular focus in this research (McCaffery et al. 2006) where RA 
performs roles with parallels to its function in the developing brain, modulating neuronal plasticity. Hippocampal function in learning and memory is dependent on plastic changes in synaptic strength, numbers of synapses and neurons, all of which can be modified and in which RA plays a role (McCaffery et al. 2006). The number of granule neurons in the dentate gyrus is modified through regulated neurogenesis (Alvarez-Buylla and Lim 2004) and this can be controlled by RA in a biphasic fashion with both a deficiency (Jacobs et al. 2006) and excess (Crandall et al. 2004) leading to diminished neurogenesis and decline in performance in a radial maze (Crandall et al. 2004). When rats are deficient in vitamin A, modification of synaptic strength through long-term potentiation is reduced together with their ability to perform in a radial maze (Misner et al. 2001; Cocco et al. 2002). Further, when the RARs are functionally removed by mutation in mice then this results in deficits in both longterm potentiation and long-term depression as well as the expected deficits in performance in hippocampal-dependent learning and memory tasks (Chiang et al. 1998). More recently it has been shown that synaptic scaling, necessary for overall homeostatic regulation of a neuron's synapses requires RA to maintain this stability, surprisingly not through RARs regulation of transcription but rather though modification of translation (Aoto et al. 2008; Poon and Chen 2008).

The RARs that mediate these events are distributed throughout the mammalian brain as has been shown extensively in the mouse and rat (Ruberte et al. 1993; Zetterstrom et al. 1994, 1999; Krezel et al. 1999) and in limited studies in the human (Rioux and Arnold 2005). Also essential are the enzymes that synthesise RA from retinol, performing this oxidation in two steps, the first step catalysed by ubiquitous retinol dehydrogenases, the final step by tissue specific retinaldehyde dehydrogenases (RALDHs) (Mey and McCaffery 2004). Both steps are essential, but in the rodent brain there is reported to be only localised RALDH expression in certain cortical neurons as well as the meninges surrounding the brain (Wagner et al. 2002; Luo et al. 2009). Although cultured neurons from the hippocampus express the RALDHs (Rioux and Arnold 2005), there is little expression of these enzymes in vivo and it is hypothesised that RA is derived from the meninges by diffusion (Sakai et al. 2004). RA levels, at least in the mouse hippocampus, must be low and the RA-regulated hippocampal events described in the mouse may require only very low levels of this paracrine hormone. The situation in the human hippocampus, however, has been unexplored. This study confirms that RALDH levels are very low in mouse neurons but, to the contrary, qPCR detects high levels of RALDH transcript in the human hippocampus and corresponding strong expression of
RALDH protein in hippocampal neurons. This implies an essential function of RA in the human hippocampus and, from its described roles in the rodent hippocampus of regulation of neuronal plasticity, this is potentially its role in the human.

\section{Methods}

Preparation of tissues

The present study was approved by the Ethics Committee of Universidade Metropolitana de Santos, SP, Brazil, and by the Brazilian Health Research Committee on April 4th 2011, under the number CONEP 16168, documents registered under the number 25000.169694/2010-18. Caudal human hippocampi from six male individuals aged 55 years or less, who did not present any neurological or psychiatric disease, were collected during necropsy procedures. Brains from individuals whose death was related to head trauma, and extensive infection, toxic, anoxic or metabolic injuries were excluded from this study. Samples from the hippocampus, measuring typically $0.5 \mathrm{~cm}^{3}$, were fixed in $10 \%$ buffered $\left(\mathrm{NaH}_{2} \mathrm{PO}_{4}\right.$ and $\left.\mathrm{Na}_{2} \mathrm{HPO}_{4}\right)$ formalin within $24 \mathrm{~h}$ from death and placed in paraffin blocks within the following $24 \mathrm{~h}$. Other samples from the same areas were collected in RNAlater RNA Stabilization Reagent (Qiagen, Venlo, The Netherlands) and stored at $4{ }^{\circ} \mathrm{C}$ for qPCR or were freshly frozen for western blot analysis. Mouse tissues were from adult male C57B16 mice aged 3 months $(n=3)$ bred from an in-house colony that were kept on a 12L:12D light cycle. These animals were perfusion fixed using $4 \%$ paraformaldehyde. All animal procedures were carried out in accordance with Home Office regulations and local ethics committee guidelines.

\section{Western blotting}

Human hippocampal protein was extracted in $0.01 \mathrm{M}$ phosphate buffer containing a protease inhibitor cocktail (Sigma) using mechanical homogenisation and three freeze-thaw cycles. Homogenates were centrifuged $10 \mathrm{~min}$ at $12,000 \mathrm{rpm}$ at $4^{\circ} \mathrm{C}$. Total protein levels in each sample were quantified by the BCA assay (Pierce) and loaded onto a $12 \%$ SDS-PAGE mini-gel, $50 \mu \mathrm{g}$ total protein per lane. After separation the proteins were transferred onto a Hybond ${ }^{\mathrm{TM}}$-ECL nitrocellulose membrane (GE Healthcare) using a Mini Trans-Blot Cell (Bio-Rad) and loading was checked with Ponceau-S (Sigma). Membranes were probed with the primary antibodies that were to be used for immunohistochemistry of the RALDH enzymes; rabbit anti-RALDH1 (Abcam 1:3,000), rabbit anti-RALDH2 $(1: 10,000)$ or rabbit anti-RALDH3 $(1: 10,000)$ overnight. 
Staining was detected using a secondary HRP anti-rabbit antibody (Sigma 1:5,000) and enhanced chemiluminescence (Millipore) incubated for $5 \mathrm{~min}$ followed by exposure to X-ray film (Thermo Fisher Scientific).

\section{Immunohistochemistry}

The samples were sectioned at $7 \mu \mathrm{m}$, onto A380-bond slides (Electron Microscopy Sciences, Hatfield PA 19440, USA) and dried overnight at $37^{\circ} \mathrm{C}$. Paraffin was removed from tissue samples with xylene and was rehydrated through decreasing ethanol concentrations $(100,95,80$ and $70 \%$ ). Antigen retrieval was achieved by microwaving samples for $10 \mathrm{~min}$ in sodium citrate buffer, $\mathrm{pH}$ 6.0. Samples were allowed to cool on the bench for $20 \mathrm{~min}$ and were then washed in $1 \times$ PBS pH 7.4, containing $1 \%$ Tween 20 (Sigma) and 1\% pooled human serum (BioSera) (from now on referred as the PBS solution). From this stage, immunohistochemistry was then carried out with two different procedures depending on the staining method.

\section{Immunohistoperoxidase detection}

The samples were incubated with $3 \% \mathrm{H}_{2} \mathrm{O}_{2}$ in methanol for 10 min to block endogenous peroxidases and subsequently washed with $1 \times$ PBS. Avidin-Biotin (Vector Labs) blocking was performed to reduce non-specific binding. Primary antibodies used were rabbit anti-RALDH1 (1:300, Abcam), rabbit anti-RALDH2 [1:2,000, (Berggren et al. 1999)], rabbit anti-RALDH3 [1:3,000, (Wagner et al. 2002)], rabbit anti-RAR $\alpha$ (1:300 Santa Cruz), rabbit anti$\operatorname{RAR} \beta$ (1:300 Santa Cruz Biotechnology) and rabbit antiRAR $\gamma$ (1:300 Santa Cruz Biotechnology). RALDH1 was raised against a rat peptide and has been shown to react with multiple tissues including human according to the manufacturer's description. RALDH2 and 3 were raised against whole protein and the RALDH2 antibody has been shown to recognise the human protein (Spiegl et al. 2008). All the RAR antibodies are raised against human epitopes and react with human tissue (Meng et al. 2011; Lu et al. 2005; Alique et al. 2007). After washing with $1 \times$ PBS, the tissue was incubated with biotinylated secondary antibodies (Sigma) for $1 \mathrm{~h}$ at room temperature. Subsequently, the slides were washed with the PBS solution and incubated for $1 \mathrm{~h}$ with Vecstatin ABC Elite (Vector Labs). After further washing, the sections were exposed to $0.05 \% 3,3^{\prime}$ diaminobenzidine (Sigma) diluted $0.1 \%$ in PBS, to visualise antibody staining. Nuclei staining was carried out with haematoxylin staining, and tissue was dehydrated through sequential ethanol concentrations followed by xylene before mounting with DPX (Sigma).
Immunofluorescent detection

Samples were incubated for $1 \mathrm{~h}$, at room temperature, with blocking solution $(1 \times$ PBS pH 7.4 containing $0.3 \%$ Tween 20, 5\% normal goat serum, 5\% bovine serum albumin and 5\% pooled human serum (Makitie et al. 2010) tissue was incubated with the primary antibody diluted in blocking solution and incubated overnight at $4^{\circ} \mathrm{C}$. Primary antibodies and incubation procedures were the same as described above. The primary antibody used in doublelabelling experiments to identify neurons was chicken antiMAP2 (1:500 Millipore).

After incubation, the slides were washed in the PBS solution. The tissue was then incubated with the secondary fluorescent antibody [anti-rabbit 1:300 (Alexa Fluor, Invitrogen) or anti-chicken 1:400 (DyLights, Stratech)] diluted in the PBS solution, for $1 \mathrm{~h}$, at room temperature. Slides were washed in the PBS solution and incubated for 1 min with $10 \%$ Sudan Black (Acros Organics) made up in $70 \%$ isopropyl alcohol to reduce auto-fluorescence (Schnell et al. 1999; Neumann and Gabel 2002). The slides were then thoroughly washed in distilled water and mounted with mounting medium containing 1,4-diazabicyclo[2.2.2]octane (DABCO, Sigma) and bisbenzimide (Sigma).

\section{Quantitative PCR}

Total RNA was extracted from hippocampal samples using a RNeasy mini kit (Qiagen) with on column DNase treatment (Qiagen). RNA was quantified using a Nanodrop spectrophotometer (Thermo Scientific). cDNA was synthesised using High Capacity RNA to cDNA Master Mix (Applied Biosystems). qPCR analysis was performed using SensiMix SYBR (Bioline) to assess the presence or absence of RALDH and RAR gene expression in human $(n=3)$ samples. Primers were designed for human analysis using human RNA sequences obtained from the NCBI gene database. The primer sequences were as follows: RALDH1 (F: CAAGG CAGTGAAGGCCGCAAGA, R: ATTGACTCCATTGTC GCCAGCAGC), RALDH2 (F: CACTGAGCAGGGTC CCCAGATTGA, R: AACCCCTTTCGGCCCAGTCCT), RALDH3 (F: CGCAACCTGGAGGTCAAGTTCACC, R: AGCCTTGTCCACGTCGGGCTTA), RAR $\alpha$ (F: GAGGG CTGTAAGGGCTTCTTCCG, R: TGAGCTCGCCCACCT CAGGC), RAR $\beta$ (F: GCTTAATCTGTGGAGACCGCC AGG, R: TGTGAGGCTTGCTGGGTCGT), RAR $\gamma$ (F: GGGGCATCAGCACTAAGGGAGCT, R: AGGCATTGG GGTGGGGACCA) and GAPDH (F: TCTTTTGCGTCG CCAGCCGA, R: AGTTAAAAGCAGCCCTGGTGAC CA) was used as an internal control standard for all human samples. Standard curves and blank controls were run for all genes. Samples were run on a LightCycler ${ }^{\circledR} 480$ (Roche) and 
analysed using LightCycler ${ }^{\circledR}$ SW 1.5 software. Analysis was performed using relative quantification and the Roche's E-method of quantification which uses standard curve derived efficiencies.

\section{Cell counting}

Photographs of slides were taken using a Nikon Eclipse E400 microscope and images captured with a QICAM Fast 1394 (QImaging) camera and analysed by Image J cell counter plugin (Image Processing and Analysis in JAVA; public domain, developed at the National Institutes of Health; NIH, USA). The total number of cells was determined by counting of cell nuclei fluorescently labelled with bisbenzamide (blue) while the number of immunolabelled cells was determined by counting of cells fluorescently labelled with either Alexa Fluor 546 (red, used for RAR or RALDH) or Alexa Fluor 488 (green, used for MAP2)-labelled secondary antibody. For each antibody of interest 100 cells, either nuclear stained (all cells) or MAP2 stained (neurons only) were counted and of these the number of cells positive for the RAR or RALDH antibodies was counted. For each antibody 6 individual samples were quantified in 3 different sections per individual and between 3 and 5 fields of view were counted. Average values of the counts were taken and standard error of the mean shown. Data were analysed using One-way ANOVA with Tukey post-hoc testing.

\section{Results}

Expression of retinoic acid synthetic enzymes in the mouse and human dentate gyrus

The RALDH enzymes are responsible for the final oxidative step to synthesise RA from vitamin A. Antibodies for these proteins have been extensively used in rodent studies; however, limited information is available as to their specificity in humans. Western blotting of human hippocampus showed that all three antibodies directed against the RALDH proteins detected proteins of the appropriate molecular weight (Fig. 1a); single bands were detected for RALDH1 (54 kDa) and RALDH3 (56 kDa), whereas two bands were evident for RALDH2 (55 and $36 \mathrm{kDa}$ ) as seen for rodent tissue and the smaller protein may represent a proteolytic fragment of the larger. In the mouse hippocampus these enzymes cannot be detected in neurons by immunohistochemistry (Wagner et al. 2002), nor their transcripts by in situ hybridization (Allen Brain Atlas http://www.brain-map.org/) and the primary source for the hippocampus is likely the meninges (Sakai et al. 2004). This low expression is confirmed here with DAB immunohistochemistry in which the mouse hippocampus is negative for RALDH3 and RALDH1 and 2 are only present in the meninges (Fig. 1b-d). Using the same immunohistochemical technique however, the human hippocampus contrasted markedly with all three RALDH proteins expressed in a proportion of cells in the dentate gyrus of the
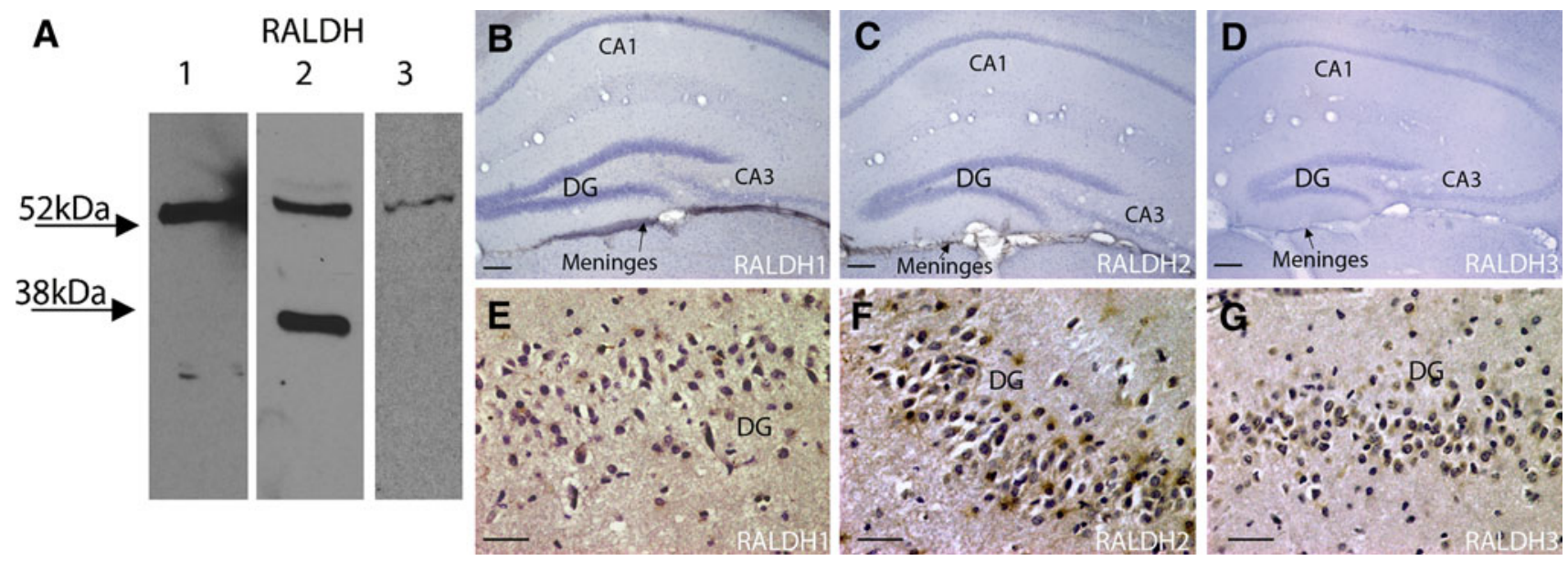

Fig. 1 Prevalence of RALDH proteins in the mouse and human hippocampus. The specificity of the RALDH antibodies to their respective proteins in the human hippocampus was verified with western blotting, identifying RALDH1 (54 kDa), RALDH2 (55 kDa) and RALDH3 (56 kDa) (a). 3,3'-diaminobenzidine (DAB) immunohistochemistry was used to determine differing expression patterns for the RALDH protein in the mouse and human hippocampus. The mouse hippocampus including the dentate gyrus (DG) showed no expression of any of the RALDHs (b-d), but RALDH1 and RALDH2 were expressed in the underlying meninges (indicated by arrows). In contrast the human hippocampus expressed all three RALDH enzymes in cells of the dentate gyrus $(\mathbf{e}-\mathbf{g})$. Scale bars $\mathbf{b}-\mathbf{d} 50 \mu \mathrm{m}$, e-g $40 \mu \mathrm{m}$ 

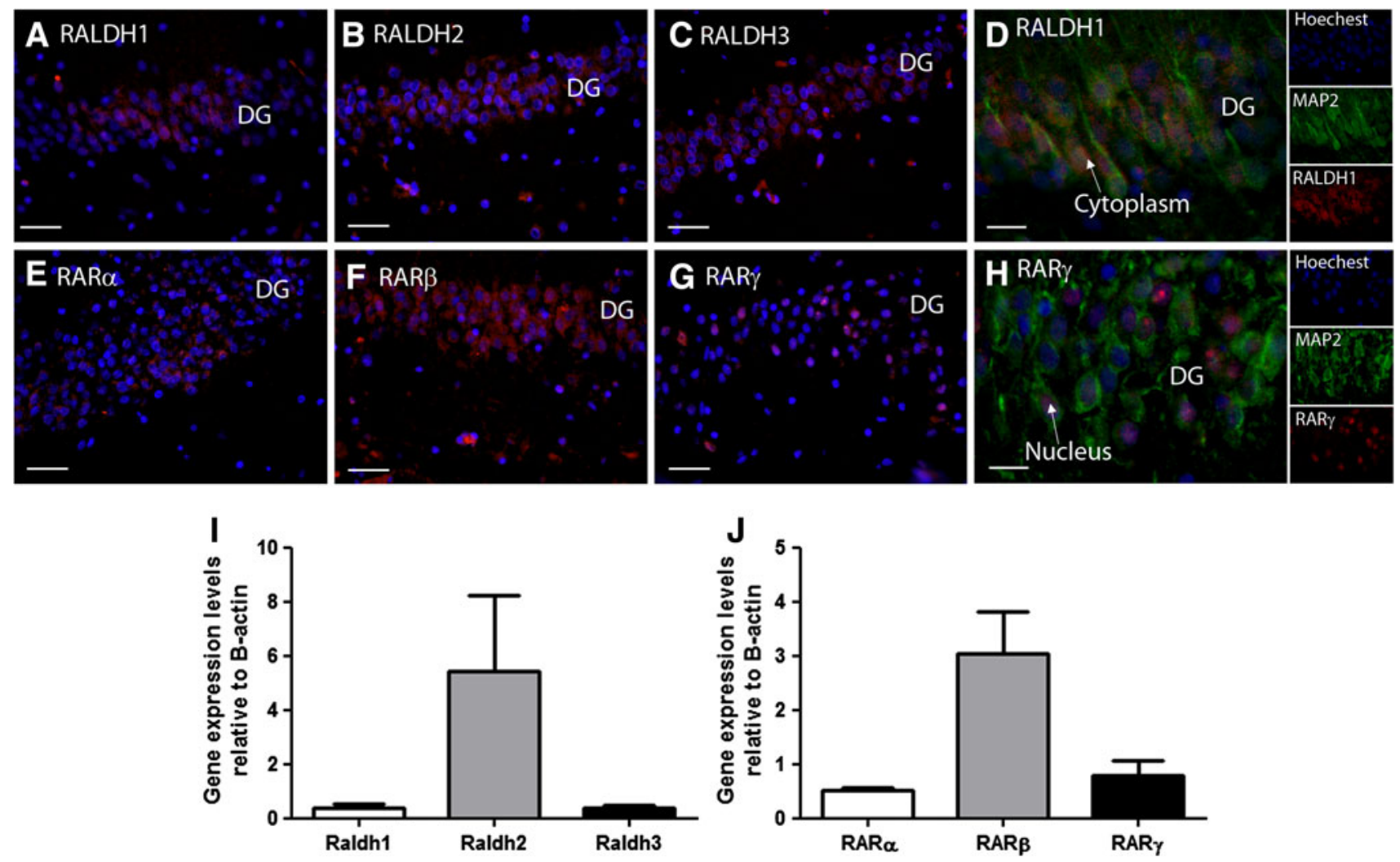

Fig. 2 Elements of the RA synthesis and signalling pathway in the human dentate gyrus. A sensitive immunofluorescence technique used for human hippocampal sections showed differing distributions of the RALDH proteins in the dentate gyrus (DG, a-c). All three proteins were present in a proportion of cells with extensive labelling for RALDH2 (b) and RALDH3 (c) with less labelling seen for RALDH1 (a). An example of immunofluorescence double labelling for RALDH1 with the neuronal marker MAP2 showed predominantly cytoplasmic (shown by arrow) but also some nuclear localization in neurons (d), the inset shows the separate colour channels for the main merged image. Immunofluorescence was used to detect the presence of $\operatorname{RAR} \alpha, \beta$ and $\gamma$ in the human hippocampus. Positive staining was

hippocampus, illustrated in Fig. 1e-g, demonstrating the capacity of these neurons to synthesise RA.

Immunofluorescent detection of retinoic acid synthetic enzymes and receptors in the human dentate gyrus

To confirm that the intense immunolabelling of RALDHs in the dentate gyrus was not the result of non-specific immunoperoxidase labelling, an immunofluorescent technique was employed based on that of Makitie et al. (2010) providing very sensitive and specific staining while effectively quenching autofluorescence. This was performed with hippocampi from six adult individuals of age less than 55 years and representative images are shown of RALDH1 (Fig. 2a), RALDH2 (Fig. 2b) and RALDH3 (Fig. 2c), demonstrating immunolabelling in cells of the dentate gyrus. Double labelling with the neuronal marker MAP2

seen for all three receptors $(\mathbf{e}-\mathbf{g})$ in the dentate gyrus. Greatest staining was observed for $\operatorname{RAR} \beta(\mathbf{f})$ followed by $\operatorname{RAR} \alpha(\mathbf{e})$ and $\operatorname{RAR} \gamma$ (g). Using immunofluorescence double labelling with MAP2, RAR $\gamma$ is shown to have a nuclear localization (shown by arrow) (h), the inset shows the separate colour channels for the main merged image. Quantitative real-time PCR showed that all RALDH genes were expressed in the hippocampus (i) and RALDH2 was particularly prominent. Similarly, all three RARs transcripts were present in the hippocampus (j) in particular RAR $\beta$. All expression levels are shown relative to the expression of the housekeeping gene $\beta$-actin. SEM are shown for an $n=3$. Scale bars $\mathbf{a}-\mathbf{c}$ and $\mathbf{e}-\mathbf{g} 40 \mu \mathrm{m}, \mathbf{d}$ and h $40 \mu \mathrm{m}$

demonstrated that the RALDHs are present in neurons, shown for RALDH1 expressed predominantly in its typical cytoplasmic location (Fig. 2d).

The importance of RA signalling in the hippocampus has been implied in the rodent from RA receptor expression [reviewed (McCaffery et al. 2006)] but very few studies have explored receptor expression in the human. All three RARs, $\alpha, \beta$ and $\gamma$ (Fig. 2e-g) were present in the human dentate gyrus. Double labelling with MAP2 showed neuronal localization as shown for $\operatorname{RAR} \gamma$ present in both the nucleus and cytoplasm implying possibly both genomic and non-genomic function (Fig. 2h) (as discussed below).

qPCR analysis of RALDHs and RARs was performed on samples of caudal hippocampus from three subjects to determine the expression of their respective mRNA transcripts. The RALDHs were identified within 23 cycles indicating substantial levels of all three enzymes with 

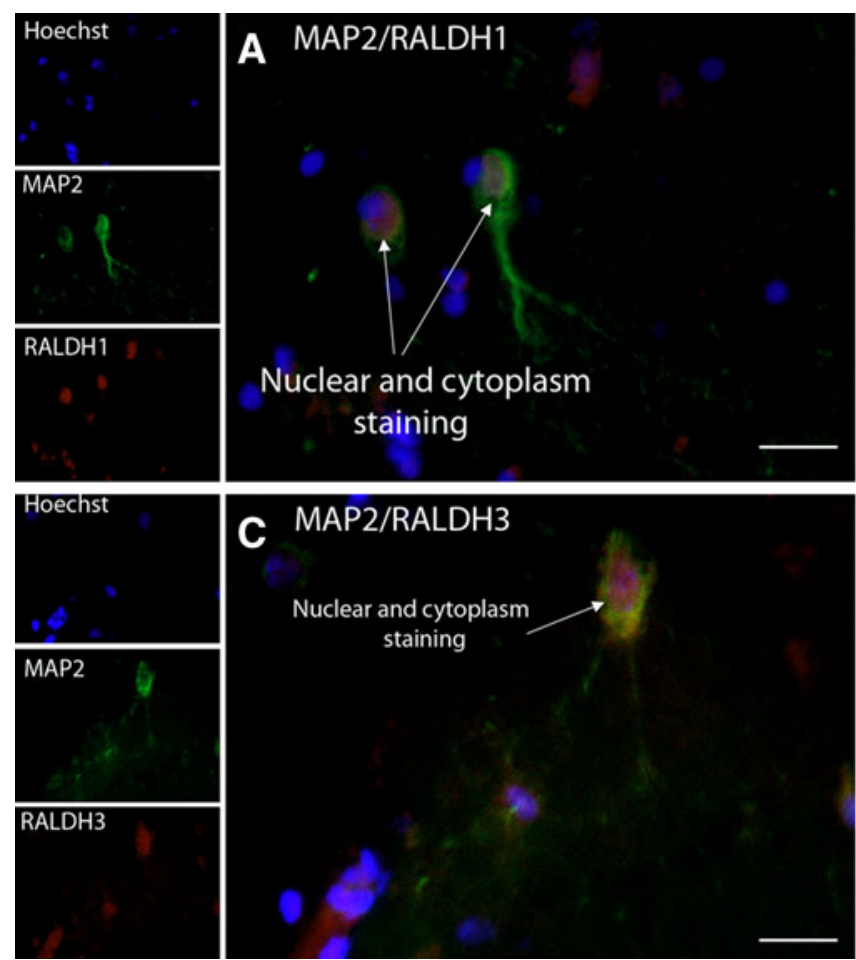

Fig. 3 RALDH1, 2 and 3 are present in neuronal cells of the human CA1 hippocampal subfield. Double labelling immunofluorescence with the neuronal marker MAP2 showed RALDH1 (a), RALDH2 (b) and RALDH3 (c) proteins present in neurons of CA1. Each image panel shows the separate colour channels as smaller inserts to the left

RALDH2 being the most prominently expressed (Fig. 2i). qPCR analysis of transcript expression by qPCR found $\operatorname{RAR} \alpha, \beta$ and $\gamma$ were expressed in the hippocampus with $\operatorname{RAR} \beta$ being the most prominent (Fig. $2 \mathrm{j}$ ).

Expression of retinoic acid synthetic enzymes and receptors in neurons of the human hippocampal CA1 subfield

RALDH1, 2 and 3 were also present in neurons of the cornu ammonis (CA) subfields of the hippocampus as determined by double-labelling with MAP2 (Fig. 3a-c) and compared with a negative control lacking RALDH primary antibody (Fig. 3d). The enzymes were predominantly localised to the cytoplasm and were also present in some cell processes, while some cells also showed nuclear localization as has been recently shown in rodent astrocytes (Wang et al. 2011).

Nuclear RARs regulate gene expression in a ligandactivated fashion (Chambon 1996) while more recently cytoplasmic RARs have been demonstrated to perform nongenomic roles, regulating various kinases (Rochette-Egly and Germain 2009) as well as protein translation (Chen et al. 2008; Poon and Chen 2008). Each RAR showed a
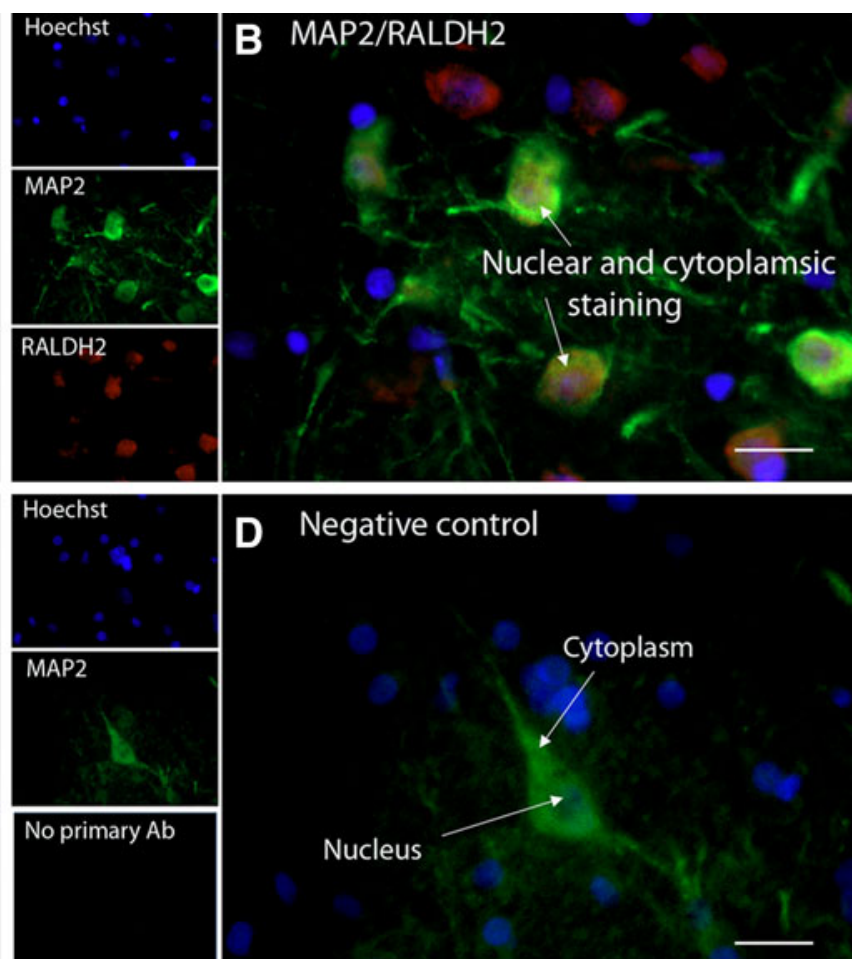

of the main merged image. The distribution of these proteins is predominantly cytoplasmic but with some expression in the nucleus (as shown by arrows in $\mathbf{a}-\mathbf{c}$ ). A negative control sample that was stained with MAP2 but no RALDH antibody showed absence of background staining (d). All scale bars $20 \mu \mathrm{m}$

distinctive subcellular distribution (Fig. 4a-c) compared with the negative control without RAR primary antibody (Fig. 4d). RAR $\alpha$ was present in the nucleus as well as showing a perinuclear distribution (Fig. 4a), RAR $\beta$ was identified in the cell nucleus and cytoplasm (Fig. 4b) and $\operatorname{RAR} \gamma$ was found predominantly in the nucleus (Fig. 4c). No RAR staining was observed in the cell processes, contrasting with in vitro cultured neurons that can show strong expression within neuronal processes (unpublished observation).

Relative number of neurons in the dentate gyrus and CA1 expressing retinoic acid synthetic enzymes and receptors

Numbers of MAP2 positive neurons in the dentate gyrus and CA1 subfields expressing either RALDHs or the RARs were counted to determine the relative distribution of these components of the RA-signalling pathway. RALDH1 was significantly less expressed in the dentate gyrus (56\%), than RALDH2 $(84 \%, P<0.001)$ or RALDH3 $(77 \%$, $P<0.01$ ) (Fig. 5a, b). A significantly smaller proportion of neurons in CA1 expressed these enzymes compared with the dentate gyrus (Fig. 5a). Similarly, the RA receptors 

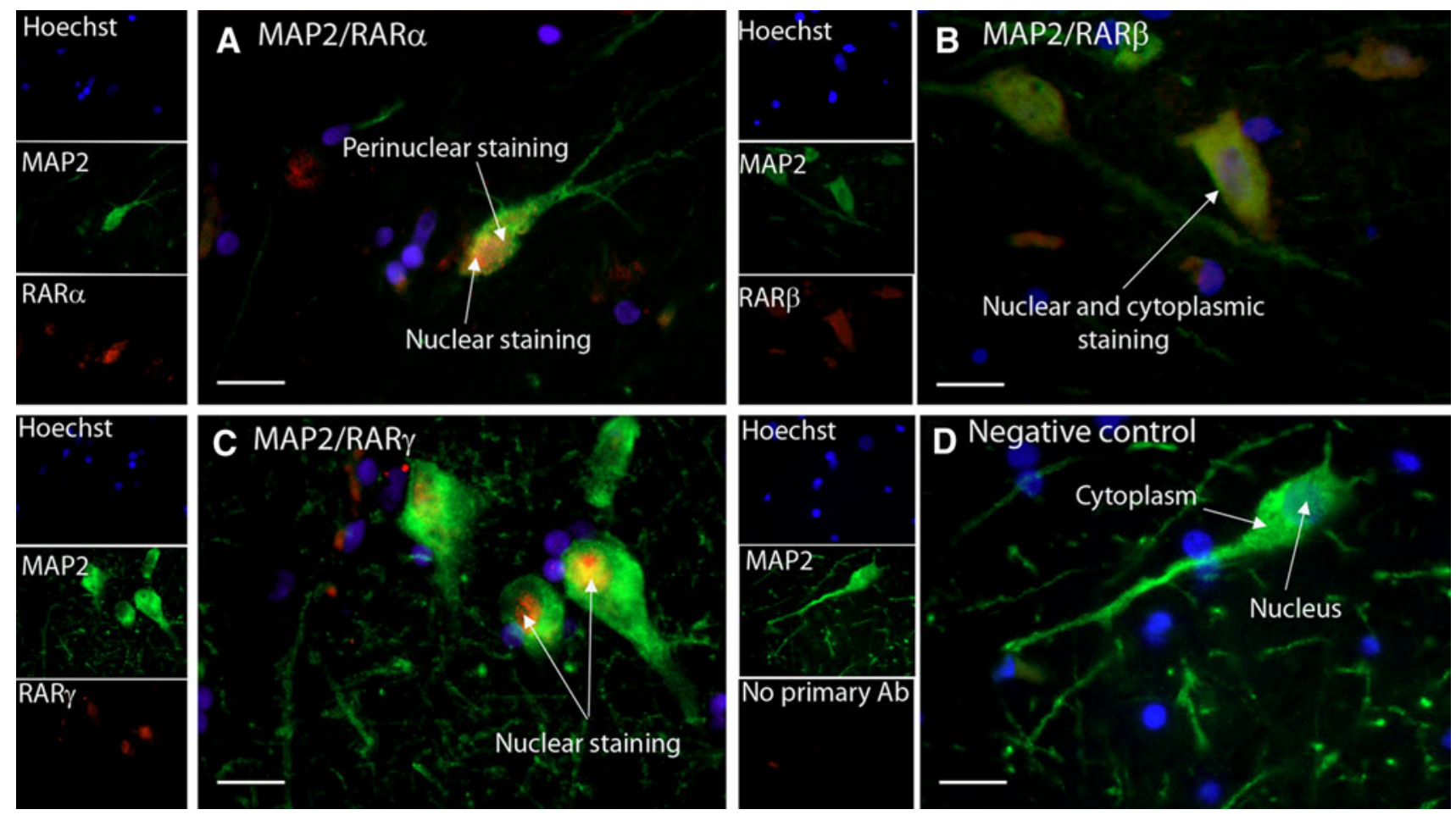

Fig. 4 Subcellular distribution of $\operatorname{RAR} \alpha, \operatorname{RAR} \beta$ and $\operatorname{RAR} \gamma$ in human CA1 neurons. RARs were shown to co-localise with neurons as determined by MAP2 double-labelling $(\mathbf{a}-\mathbf{c})$. Each image panel shows the separate colour channels as smaller inserts to the left of the main merged image. RAR $\alpha$ protein was observed in the nucleus and the perinuclear region (as shown by arrows, a), $\operatorname{RAR} \beta$ was observed

both in the nucleus and the surrounding cytoplasm of neurons (as shown by arrow, b) and RAR $\gamma$ was detected in neuronal nuclei (as shown by arrows, c). A negative control sample that was stained with MAP2 but no RAR antibody was run alongside the positive samples (d). All scale bars $20 \mu \mathrm{m}$

were also expressed in significantly $(P<0.001)$ fewer neurons in the CA1 subfield compared with the dentate gyrus $(P<0.001)$ (Fig. 5b).

\section{Discussion}

This study shows the strong expression in the human hippocampus of the components required for RA signalling; both the enzymes necessary for RA synthesis as well as the receptors required to respond to the signal. This is the first report to describe the RA synthetic enzymes in the human brain, finding varying levels of the three subtypes, RALDH1, 2 and 3, in hippocampal neurons. Given that the RALDH expression correlates very well with localised regions of RA synthesis (Niederreither et al. 1997; Swindell et al. 1999; Wagner et al. 2002) and mutation of RALDHs completely eliminate RA synthesis [as reviewed (Duester 2008)] this implies these neurons are capable of generating RA. This contrasted to the complete lack of these enzymes in mouse hippocampal neurons, the probable source of RA being the nearby meninges (Sakai et al. 2004). Of the receptors, $\operatorname{RAR} \alpha, \beta$ and $\gamma$ could be detected in neurons in the dentate gyrus while a smaller proportion

of neurons within CA1 expressed these receptors. This contrasts with mouse in which $\mathrm{RAR} \gamma$ is the only receptor present in the dentate gyrus while in the CA1/CA3 subfields $\operatorname{RAR} \alpha$ and $\gamma$ are expressed as described by Krezel et al. (1999). They describe the importance of examining RA receptor protein expression, as opposed to transcript, because of the surprisingly large discrepancies in certain regions of the brain presumably indicating extensive posttranscriptional regulation of the RA receptors (Krezel et al. 1999). Very few papers have described RA receptors in the human brain, although Rioux and Arnold reported RAR $\alpha$ and $\mathrm{RAR} \gamma$ in only approximately $12 \%$ of granule neurons and $\operatorname{RAR} \alpha$ in some neurons of the hippocampal subfields (Rioux and Arnold 2005). However, this paper used immunohistochemistry in the absence of antigen retrieval which is likely to provide only low sensitivity of detection in contrast to the high sensitivity of the immunofluorescent technique employed in this study, comparable to the methods used in rodent model species. The high expression of both receptors and RA synthetic enzymes compared with mouse models implies a crucial function in the human hippocampus. One recently discovered potential function for RA in the hippocampus is regulation of synaptic scaling. 

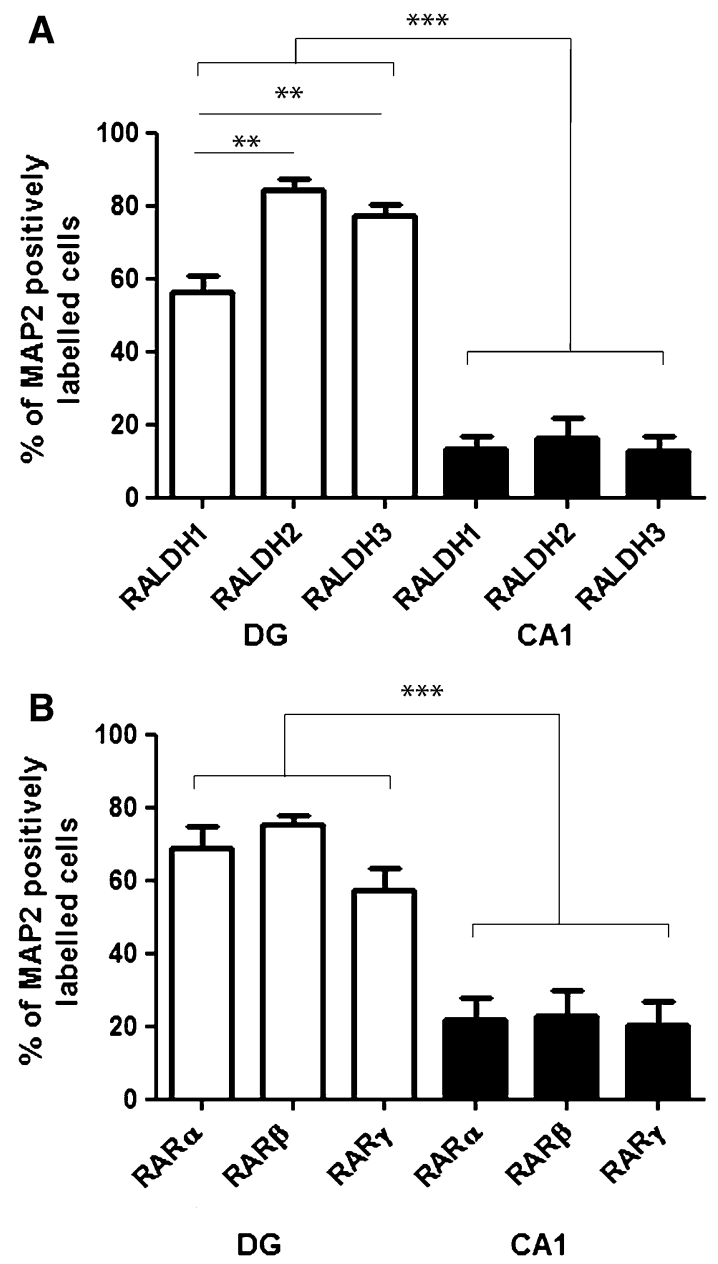

Fig. 5 Quantification of neuronal RALDH and RAR expression. Neurons double labelled for MAP2 and RALDH1-3 or MAP2 and $\operatorname{RAR} \alpha-\gamma$ were quantified in the dentate gyrus and CA1 sub-regions of the human hippocampus. A comparison of the number of RALDH positive neurons in the dentate gyrus showed that RALDH1 was significantly less expressed than RALDH2 and RALDH3 in MAP2positive cells (a). When RALDH positive cells were compared between the hippocampal sub-fields there were significantly more stained neurons in the dentate gyrus than in CA1. Evaluation of RARpositive neurons showed no differences within sub-fields but a significant difference between areas, with CA1 containing less RARpositive MAP2 cells than the dentate gyrus (b). $* * P<0.01$ and $* * * P<0.001$

Synaptic scaling is one mechanism providing balance to neuronal firing rates, maintaining homeostasis within neuronal networks (Turrigiano 2008). The regulatory system includes transient synthesis and insertion of AMPA receptors at synapses (Ju et al. 2004; Sutton et al. 2006). Regulated RA synthesis in neurons has been proposed as a mechanism to control this process; when the action potential of cultured neurons is blocked with tetrodotoxin together with a block of NMDA receptors with aminophosphonovalerate this induces synaptic scaling (Ju et al. 2004; Sutton et al. 2006) proposed to be mediated by a local increase in RA synthesis promoting local translation of AMPA receptor (Aoto et al. 2008). In contrast to the majority of RA's actions through transcriptional regulation via RA receptors in the nucleus, this is a non-genomic mechanism in which RAR $\alpha$ directly interacts with specific mRNAs to inhibit translation, this inhibition being released on binding to RA (Poon and Chen 2008) in a process that also involves the fragile $\mathrm{X}$ protein FMRP (Soden and Chen 2010). Interestingly, in the human hippocampus it is $\operatorname{RAR} \beta$ detected in the cytoplasm, while $\operatorname{RAR} \alpha$ and $\gamma$ tend to be restricted to the nucleus; thus $\operatorname{RAR} \beta$ may be more crucial for such non-genomic functions. It is proposed that RALDH1 catalyses RA synthesis for synaptic scaling and high levels of RALDH1 are reported in cultured mouse hippocampal neurons (Aoto et al. 2008). However, this new study and those of others (Wagner et al. 2002) show that none of the RALDHs are strongly expressed in endogenous rodent hippocampal neurons, and these plastic processes must rely on only low levels of RA. We now show, however, that human neurons in situ show strong RALDH expression and synaptic scaling may thus be mediated by endogenous RA in the human hippocampus.

Controversy has developed over the effect of RA on the human brain because of the use of the 13-cis isomer of RA as the active agent in the acne drug isotretinoin. Although it is clear that there are a number of adverse effects in the CNS, the most common being headache (Bremner and McCaffery 2008), many studies have linked the onset of depression with such treatment (Hazen et al. 1983; Gatti and Serri 1991; Jick et al. 2000; Bremner et al. 2005; Azoulay et al. 2008) while other studies have found the contrary (Rubinow et al. 1987; Ng et al. 2002; Cohen et al. 2007; Bozdag et al. 2009; McGrath et al. 2010). One profound problem in resolving this quandary is the difficulty in untangling the psychosocial influence of severe acne with the potential effects of the drug. Understanding the biological effects of RA on the brain is thus crucial. Rodent animal studies have shown the requirement of retinoids on functions as diverse as learning and memory performance (Etchamendy et al. 2001), sleep (Maret et al. 2005) and mesolimbic system-driven locomotion (Krezel et al. 1998); deficits in all these systems result from a reduction in RA signalling. Not just deficiency but excess RA also disrupts RA signalling and treatment of mice with RA at the same dose used for acne treatment alters hippocampal neurogenesis, leading to decreased numbers of newborn neurons together with a reduced performance in the radial maze test (Crandall et al. 2004). Similarly, treatment of rats with RA also leads to degradation in performance in learning and memory tests (Dopheide and Morgan 2008) while others have reported an increase in anxiety like behaviour (Cai et al. 2010). Despite these multiple effects by RA on the CNS, its influence on 
depression-like behaviour in the rodent is less clear with several studies pointing to an increase in some depressivelike behaviours (O'Reilly et al. 2006; Trent et al. 2009) with others studies showing no change (Ferguson et al. 2005, 2007). One possible explanation for variation in result between studies is the baseline of RA signallingRA exhibits a U-shaped curve in its toxicity, with detrimental effects in both deficiency and excess and endogenous levels crucially influence the possible harmful effect of an exogenous dose. The high levels of RA-synthesizing enzymes in the human hippocampus likely results in a very different response of the CNS to drugs such as isotretinoin compared with rodent models, where the expression of these enzymes is much lower. This needs to be taken into account when it comes to interpretation of these models but almost certainly means that the human CNS will have an altered sensitivity to RA. Further, the likelihood of high levels of RA synthesis in the human hippocampus will have consequences for the reliance of the brain on vitamin A. It is known that vitamin A levels in the brain can decline with age (Craft et al. 2004) while the carotenoid form of vitamin $\mathrm{A}$ is protective against cognitive decline (Grodstein et al. 2007) and retinoic acid has been reported to provide protection from Alzheimer's disease (Corcoran et al. 2004; Ono et al. 2004; Husson et al. 2006; Brouillette and Quirion 2007; Donmez et al. 2010; Shudo et al. 2009). The human hippocampus may have a lower resilience to a decline in vitamin A than rodent model species.

Acknowledgments Funding was provided by the Wellcome Trust and Tenovus Scotland. Prof Fragoso is the recipient of a Senior Scientist grant from the Brazilian National Council for Scientific and Technological Development (CNPq, 201488/2010-8). The authors would like to thank Patrick Stoney for designing the qPCR primers and Dr Luis Antonio Silva, Clinical Director of Hospital Guilherme Alvaro for all his support.

Open Access This article is distributed under the terms of the Creative Commons Attribution Noncommercial License which permits any noncommercial use, distribution, and reproduction in any medium, provided the original author(s) and source are credited.

\section{References}

Alique M, Herrero JF, Lucio-Cazana FJ (2007) All-trans retinoic acid induces COX-2 and prostaglandin E2 synthesis in SH-SY5Y human neuroblastoma cells: involvement of retinoic acid receptors and extracellular-regulated kinase 1/2. J Neuroinflammation 4:1

Alvarez-Buylla A, Lim DA (2004) For the long run: maintaining germinal niches in the adult brain. Neuron 41(5):683-686

Aoto J, Nam CI, Poon MM, Ting P, Chen L (2008) Synaptic signaling by all-trans retinoic acid in homeostatic synaptic plasticity. Neuron 60:308-320

Azoulay L, Blais L, Koren G, LeLorier J, Berard A (2008) Isotretinoin and the risk of depression in patients with acne vulgaris: a case-crossover study. J Clin Psychiatry 69:526-532
Bell NH (1985) Vitamin D-endocrine system. J Clin Invest 76:1-6

Berggren K, McCaffery P, Drager U, Forehand CJ (1999) Differential distribution of retinoic acid synthesis in the chicken embryo as determined by immunolocalization of the retinoic acid synthetic enzyme, RALDH-2. Dev Biol 210:288-304

Blomhoff R (1994) Overview of vitamin A metabolism and function. In: Blomhoff $\mathrm{R}$ (ed) Vitamin A in health and disease introduction. Marcel Dekker Inc, New York, pp 1-35

Bozdag KE, Gulseren S, Guven F, Cam B (2009) Evaluation of depressive symptoms in acne patients treated with isotretinoin. J Dermatolog Treat 20:293-296

Bremner JD, McCaffery P (2008) The neurobiology of retinoic acid in affective disorders. Prog Neuropsychopharmacol Biol Psychiatry 32:315-331

Bremner JD, Fani N, Ashraf A, Votaw JR, Brummer ME, Cummins T, Vaccarino V, Goodman MM, Reed L, Siddiq S, Nemeroff CB (2005) Functional brain imaging alterations in acne patients treated with isotretinoin. Am J Psychiatry 162:983-991

Brouillette J, Quirion R (2007) Transthyretin: a key gene involved in the maintenance of memory capacities during aging. Neurobiol Aging 29:1721-1732

Cai L, Yan XB, Chen XN, Meng QY, Zhou JN (2010) Chronic alltrans retinoic acid administration induced hyperactivity of HPA axis and behavioral changes in young rats. Eur Neuropsychopharmacol 20:839-847

Chambon P (1996) A decade of molecular biology of retinoic acid receptors. Faseb J 10:940-954

Chen N, Onisko B, Napoli JL (2008) The nuclear transcription factor RARalpha associates with neuronal RNA granules and suppresses translation. J Biol Chem 283:20841-20847

Chiang MY, Misner D, Kempermann G, Schikorski T, Giguere V, Sucov HM, Gage FH, Stevens CF, Evans RM (1998) An essential role for retinoid receptors RARbeta and RXRgamma in long- term potentiation and depression. Neuron 21:13531361

Cocco S, Diaz G, Stancampiano R, Diana A, Carta M, Curreli R, Sarais L, Fadda F (2002) Vitamin A deficiency produces spatial learning and memory impairment in rats. Neuroscience 115:475482

Cohen J, Adams S, Patten S (2007) No association found between patients receiving isotretinoin for acne and the development of depression in a Canadian prospective cohort. Can J Clin Pharmacol 14:e227-e233

Corcoran JP, So PL, Maden M (2004) Disruption of the retinoid signalling pathway causes a deposition of amyloid beta in the adult rat brain. Eur J Neurosci 20:896-902

Craft NE, Haitema TB, Garnett KM, Fitch KA, Dorey CK (2004) Carotenoid, tocopherol, and retinol concentrations in elderly human brain. J Nutr Health Aging 8:156-162

Crandall J, Sakai Y, Zhang J, Koul O, Mineur Y, Crusio WE, McCaffery P (2004) 13-cis-retinoic acid suppresses hippocampal cell division and hippocampal-dependent learning in mice. Proc Natl Acad Sci USA 101:5111-5116

Donmez G, Wang D, Cohen DE, Guarente L (2010) SIRT1 suppresses beta-amyloid production by activating the alphasecretase gene ADAM10. Cell 142:320-332

Dopheide MM, Morgan RE (2008) Isotretinoin (13-cis-retinoic acid) alters learning and memory, but not anxiety-like behavior, in the adult rat. Pharmacol Biochem Behav 91:243-251

Duester G (2008) Retinoic acid synthesis and signaling during early organogenesis. Cell 134:921-931

Etchamendy N, Enderlin V, Marighetto A, Vouimba RM, Pallet V, Jaffard R, Higueret P (2001) Alleviation of a selective agerelated relational memory deficit in mice by pharmacologically induced normalization of brain retinoid signaling. J Neurosci 21:6423-6429 
Ferguson SA, Cisneros FJ, Gough B, Hanig JP, Berry KJ (2005) Chronic oral treatment with 13-cis-retinoic acid (isotretinoin) or all-trans-retinoic acid does not alter depression-like behaviors in rats. Toxicol Sci 87:451-459

Ferguson SA, Cisneros FJ, Hanig JP, Berry KJ (2007) Oral treatment with ACCUTANE does not increase measures of anhedonia or depression in rats. Neurotoxicol Teratol 29:642-651

Gatti S, Serri F (1991) Acute depression from isotretinoin. J Am Acad Dermatol 25:132

Glass CK (1996) Some new twists in the regulation of gene expression by thyroid hormone and retinoic acid receptors. J Endocrinol 150:349-357

Grodstein F, Kang JH, Glynn RJ, Cook NR, Gaziano JM (2007) A randomized trial of beta carotene supplementation and cognitive function in men: the Physicians' Health Study II. Arch Intern Med 167:2184-2190

Hazen PG, Carney JF, Walker AE, Stewart JJ (1983) Depression-a side effect of 13-cis-retinoic acid therapy. J Am Acad Dermatol 9:278-279

Husson M, Enderlin V, Delacourte A, Ghenimi N, Alfos S, Pallet V, Higueret P (2006) Retinoic acid normalizes nuclear receptor mediated hypo-expression of proteins involved in beta-amyloid deposits in the cerebral cortex of vitamin A deprived rats. Neurobiol Dis 23:1-10

Jacobs S, Lie DC, Decicco KL, Shi Y, Deluca LM, Gage FH, Evans RM (2006) Retinoic acid is required early during adult neurogenesis in the dentate gyrus. Proc Natl Acad Sci USA 103:3902-3907

Jick SS, Kremers HM, Vasilakis-Scaramozza C (2000) Isotretinoin use and risk of depression, psychotic symptoms, suicide, and attempted suicide. Arch Dermatol 136:1231-1236

Ju W, Morishita W, Tsui J, Gaietta G, Deerinck TJ, Adams SR, Garner CC, Tsien RY, Ellisman MH, Malenka RC (2004) Activity-dependent regulation of dendritic synthesis and trafficking of AMPA receptors. Nat Neurosci 7:244-253

Krezel W, Ghyselinck N, Samad TA, Dupe V, Kastner P, Borrelli E, Chambon P (1998) Impaired locomotion and dopamine signaling in retinoid receptor mutant mice. Science 279:863-867

Krezel W, Kastner P, Chambon P (1999) Differential expression of retinoid receptors in the adult mouse central nervous system. Neuroscience 89:1291-1300

Lu M, Mira-y-Lopez R, Nakajo S, Nakaya K, Jing Y (2005) Expression of estrogen receptor alpha, retinoic acid receptor alpha and cellular retinoic acid binding protein II genes is coordinately regulated in human breast cancer cells. Oncogene 24:4362-4369

Luo T, Wagner E, Drager UC (2009) Integrating retinoic acid signaling with brain function. Dev Psychol 45:139-150

Makitie LT, Kanerva K, Polvikoski T, Paetau A, Andersson LC (2010) Brain neurons express ornithine decarboxylase-activating antizyme inhibitor 2 with accumulation in Alzheimer's disease. Brain Pathol 20:571-580

Maret S, Franken P, Dauvilliers Y, Ghyselinck NB, Chambon P, Tafti M (2005) Retinoic acid signaling affects cortical synchrony during sleep. Science 310:111-113

McCaffery PJ, Adams J, Maden M, Rosa-Molinar E (2003) Too much of a good thing: retinoic acid as an endogenous regulator of neural differentiation and exogenous teratogen. Eur J Neurosci $18: 457-472$

McCaffery P, Zhang J, Crandall JE (2006) Retinoic acid signaling and function in the adult hippocampus. J Neurobiol 66:780-791

McGrath EJ, Lovell CR, Gillison F, Darvay A, Hickey JR, Skevington SM (2010) A prospective trial of the effects of isotretinoin on quality of life and depressive symptoms. Br J Dermatol 163:1323-1329
Meng QY, Chen XN, Zhao J, Swaab DF, Zhou JN (2011) Distribution of retinoic acid receptor-alpha immunoreactivity in the human hypothalamus. Neuroscience 174:132-142

Mey J, McCaffery P (2004) Retinoic acid signaling in the nervous system of adult vertebrates. Neuroscientist 10:409-421

Misner DL, Jacobs S, Shimizu Y, de Urquiza AM, Solomin L, Perlmann T, De Luca LM, Stevens CF, Evans RM (2001) Vitamin A deprivation results in reversible loss of hippocampal long-term synaptic plasticity. Proc Natl Acad Sci USA 98:11714-11719

Neumann M, Gabel D (2002) Simple method for reduction of autofluorescence in fluorescence microscopy. J Histochem Cytochem 50:437-439

Ng CH, Tam MM, Celi E, Tate B, Schweitzer I (2002) Prospective study of depressive symptoms and quality of life in acne vulgaris patients treated with isotretinoin compared to antibiotic and topical therapy. Australas J Dermatol 43:262-268

Niederreither K, McCaffery P, Drager UC, Chambon P, Dolle P (1997) Restricted expression and retinoic acid-induced downregulation of the retinaldehyde dehydrogenase type 2 (RALDH2) gene during mouse development. Mech Dev 62:67-78

Ono K, Yoshiike Y, Takashima A, Hasegawa K, Naiki H, Yamada M (2004) Vitamin A exhibits potent antiamyloidogenic and fibrildestabilizing effects in vitro. Exp Neurol 189:380-392

O'Reilly KC, Shumake J, Gonzalez-Lima F, Lane MA, Bailey SJ (2006) Chronic administration of 13-cis-retinoic acid increases depression-related behavior in mice. Neuropsychopharmacology 31:1919-1927

Poon MM, Chen L (2008) Retinoic acid-gated sequence-specific translational control by RARalpha. Proc Natl Acad Sci USA 105:20303-20308

Rioux L, Arnold SE (2005) The expression of retinoic acid receptor alpha is increased in the granule cells of the dentate gyrus in schizophrenia. Psychiatry Res 133:13-21

Rochette-Egly C, Germain P (2009) Dynamic and combinatorial control of gene expression by nuclear retinoic acid receptors (RARs). Nucl Recept Signal 7:e005

Ruberte E, Friederich V, Chambon P, Morriss-Kay G (1993) Retinoic acid receptors and cellular retinoid binding proteins. III. Their differential transcript distribution during mouse nervous system development. Development 118:267-282

Rubinow DR, Peck GL, Squillace KM, Gantt GG (1987) Reduced anxiety and depression in cystic acne patients after successful treatment with oral isotretinoin. J Am Acad Dermatol 17:25-32

Sakai Y, Crandall JE, Brodsky J, McCaffery P (2004) 13-cis Retinoic acid (accutane) suppresses hippocampal cell survival in mice. Ann N Y Acad Sci 1021:436-440

Schnell SA, Staines WA, Wessendorf MW (1999) Reduction of lipofuscin-like autofluorescence in fluorescently labeled tissue. J Histochem Cytochem 47:719-730

Shaffer PL, Gewirth DT (2004) Vitamin D receptor-DNA interactions. Vitam Horm 68:257-273

Shudo K, Fukasawa H, Nakagomi M, Yamagata N (2009) Towards retinoid therapy for Alzheimer's disease. Curr Alzheimer Res 6:302-311

Soden ME, Chen L (2010) Fragile X protein FMRP is required for homeostatic plasticity and regulation of synaptic strength by retinoic acid. J Neurosci 30:16910-16921

Spiegl N, Didichenko S, McCaffery P, Langen H, Dahinden CA (2008) Human basophils activated by mast cell-derived IL-3 express retinaldehyde dehydrogenase-II and produce the immunoregulatory mediator retinoic acid. Blood 112:3762-3771

Sporn MB, Roberts AB, Goodman DS (1994) The retinoids: biology, chemistry, and medicine, 2nd edn. Raven Press, New York

Sutton MA, Ito HT, Cressy P, Kempf C, Woo JC, Schuman EM (2006) Miniature neurotransmission stabilizes synaptic function 
via tonic suppression of local dendritic protein synthesis. Cell 125:785-799

Swindell EC, Thaller C, Sockanathan S, Petkovich M, Jessell TM, Eichele G (1999) Complementary domains of retinoic acid production and degradation in the early chick embryo. Dev Biol 216:282-296

Trent S, Drew CJ, Mitchell PJ, Bailey SJ (2009) Chronic treatment with 13-cis-retinoic acid changes aggressive behaviours in the resident-intruder paradigm in rats. Eur Neuropsychopharmacol 19:876-886

Turrigiano GG (2008) The self-tuning neuron: synaptic scaling of excitatory synapses. Cell 135:422-435

Wagner E, Luo T, Drager UC (2002) Retinoic acid synthesis in the postnatal mouse brain marks distinct developmental stages and functional systems. Cereb Cortex 12:1244-1253
Wang C, Kane MA, Napoli JL (2011) Multiple retinol and retinal dehydrogenases catalyze all-trans-retinoic acid biosynthesis in astrocytes. J Biol Chem 286:6542-6553

Zetterstrom RH, Simon A, Giacobini MMJ, Ericksson U, Olson L (1994) Localization of cellular retinoid-binding proteins suggests specific roles for retinoids in the adult central nervous system. Neuroscience 62:899-918

Zetterstrom RH, Lindqvist E, Mata de Urquiza A, Tomac A, Eriksson U, Perlmann T, Olson L (1999) Role of retinoids in the CNS: differential expression of retinoid binding proteins and receptors and evidence for presence of retinoic acid. Eur $\mathbf{J}$ Neurosci 11:407-416 